Twenty-First Century Papers:

Online Working Papers from the

Center for 21st Century Studies

University of Wisconsin-Milwaukee

www.21st.uwm.edu

\title{
Bloody Language: \\ Clashes and Constructions of Linguistic Nationalism in India
}

\author{
A. Aneesh
}




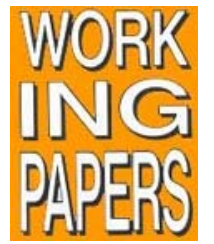

Twenty-First Century Papers: Online Working Papers from the Center for 21st Century Studies ISSN 1545-6161 University of Wisconsin-Milwaukee P.O. Box 413 Milwaukee, WI 53201 414.229.4141 (voice) 414.229 .5964 (fax) http://www.21st.uwm.edu ctr21cs@uwm.edu

Interim Director: Merry Wiesner-Hanks

The Center for 21st Century Studies, a UW System Center of Excellence at the University of WisconsinMilwaukee, is a postdoctoral research institute founded in 1968 to foster cross-disciplinary research in the humanities. This series of occasional, online Working Papers provides a forum for rapid distribution of ideas in texts that are not yet ready or suitable for publication in more formal academic publications, but still offer valuable content. Usually the authors of Center Working Papers will be Center fellows, invited speakers, or others with significant ties to the Center, although we reserve the right to make exceptions. We regret that we are unable to consider unsolicited submissions.

\title{
Bloody Language: \\ Clashes and Constructions of Linguistic Nationalism in India
}

\author{
A. Aneesh \\ Assistant Professor of Sociology and Global Studies \\ University of Wisconsin-Milwaukee
}

Twenty-First Century Papers

Online working papers from the Center for 21st Century Studies

University of Wisconsin-Milwaukee

Number 12

October 2009

(C) Copyright 2009 by the Center for 21st Century Studies

All rights reserved 


\title{
Bloody Language*
}

\section{Clashes and Constructions of Linguistic Nationalism in India}

\author{
Forthcoming in Sociological Forum, 25,2, June 2010
}

\author{
A. Aneesh \\ Assistant Professor of Sociology and Global Studies \\ University of Wisconsin-Milwaukee \\ Email: aneesh@uwm.edu
}

- This study was facilitated by the Center for $21^{\text {st }}$ Century Studies at the University of WisconsinMilwaukee. I thank Merry Wiesner-Hanks, Kate Kramer, Michelle Caswell and my co-fellows at the Center for their patient feedback and suggestions. I would also like to thank Erica Bornstein, Jozsef Borocz, Eviatar Zerubavel, and Sociological Forum's editors and anonymous reviewers for their immensely helpful comments. Direct correspondence to A. Aneesh, University of Wisconsin-Milwaukee. E-mail: aneesh@uwm.edu. 


\title{
BLOODY LANGUAGE:
}

\section{Clashes and Constructions of Linguistic Nationalism in India}

\author{
A. Aneesh, University of Wisconsin- \\ Milwaukee, aneesh@uwm.edu
}

On August 14, 1947, India's first Prime Minister Jawaharlal Nehru gave a famous speech on the eve of India's independence: "Long years ago we made a tryst with destiny, and now the time comes when we shall redeem our pledge, not wholly or in full measure, but very substantially. At the stroke of the midnight hour, when the world sleeps, India will awake to life and freedom." For Nehru, the promise of modernity was finally at hand, as India became an independent nation of "sovereign people," free from more than a century of colonial rule. Paradoxically, this putative sovereignty of single nationhood was disfigured by the "accompanying" violence that rent asunder the social fabric of India. The partition of India consumed about one million lives, and turned many more into refugees in their newly assigned nations: India and Pakistan. What was described as "the contradictory nature of the reality of 15 August 1947" (Chandra 1988, p. 487), however, no longer appears paradoxical or contradictory at all. Indeed, the nation-state centered project of modernity (Albrow 1997), many argue, is tightly linked with the politics and clashes of identity (Das 1990; Pandey 1990; Vail 1989).

Taking a close look at the formation of India and Pakistan as nations, this article explores the emergence of Hindi and Urdu as two distinct national languages formed out of the same dialect - Khari Boli - under the pressure of conflicting national aspirations of nineteenth century South Asia. To exaggerate its differences from the Persianized Urdu, modern Hindi was led to develop a Sanskritized version of Khari Boli. 
Persian and Devanagari scripts respectively gave them their distinctive looks. The article examines the history of the production of Modern Hindi in connection with the nationalist project of India. Evidently, the violence of partition was not perpetrated over a single fault line of religion; conflicts over language were also part of the long and often riotous politics of identity in the region (King 1994). Through historical inquiry into the institutional production of Modern Hindi, this article adds to the rich body of literature on ethnic and identity conflicts.

The unprecedented scale of violence, mostly, but not entirely, between Hindus and Muslims, could be read in two radically different ways. On the one hand, it could be seen as a full-scale eruption of preexisting religious conflict, prompting the development of two separate nations. On the other hand, one could argue that nations came to exist, not because of pre-existing ethnic divides, but because of highly modern processes of communicative integration that made the categorization of populations possible. Thus, the prior Hindu-Muslim conflicts did not lead to separate nations; rather, the conflicts were caused by the projects of two nation-states. The above two approaches inform most of the scholarship on origins of nationalism, ranging from a view that "nations" and "nationalism" have old roots and have always existed in history as "units," "sentiment," or "ethnie" (Fishman 1968; Geertz 1963; Hutchinson 2000; Shils 1957; Smith 1987) to the view that the origins of nationalism are demonstrably modern (Anderson 1991; Gellner 1983; Hobsbawm 1992). Both kinds of analyses refute the essentialist invocations of nationalism and nationalist rhetoric about some underlying, pre-existing, natural being of the nation.

Drawing upon recent studies in cognitive sociology (DiMaggio 1997; Zerubavel 1997), I propose a compromise between primeval and modernist approaches to nationalism, or between, what Brubaker et al. (2004) have called, primordial and circumstantial understandings of ethnicity. Agreeing with the first approach that a variety of religious and ethnic conflicts have existed long before the rise of modern nation-states, I avoid discounting prior sentiments and symbolic forms that tend to 
inform modern nation states. Yet, I also argue against subsuming modern nations under pre-existing modes of collective life. After all, modern nations are quite different from previous dynastic realms and empires (Anderson 1991). To solve the dilemma, I seek to shift the study of nation from an analysis centered on its origins or its substantive and foundational aspects to an investigation focused on mechanisms of boundary construction. The cognitive approach, as Brubaker et al. (2004, p. 51) argue, makes it apparent that "primordialist and circumstantialist accounts need not be mutually exclusive. The former can help explain the seemingly universal tendency to naturalize and essentialize real or imputed human differences, while the latter can help explain how ethnicity becomes relevant or salient in particular contexts."

In step with the cognitive turn in the study of ethnicity, race and nation (Aneesh 2001; Brubaker 2001; Brubaker et al. 2004), I identify a specific frame of reference that allows the flux of linguistic, religious, and ethnic landscapes to be perceived as bounded and unified entities like nations, races and religions. This socio-cognitive frame of what I call total closure promises a conceptual apparatus that may explain how the world becomes a collection of neatly divisible, bounded, closed substances. The cognitive turn should not be read as a return to the philosophy of consciousness where the psychic or conscious anchorage is assigned an ontological priority over the social. Instead, I use Goffman's (1974) term frame as a conceptual device that denotes a structural coupling (Luhmann 1984) between psychological schemas and social categories, emphasizing how nations, ethnicities or races are at once cognitive and social events. The success of the national system lies in its emotional appeal as well as institutional organization, in its coupling of cognitive and social structures, as I hope to show in the context of linguistic nationalism.

The frame-theoretic approach allows me to go beyond the debate whether nations grow out of some presumed ethnic, linguistic, religious foundations. Instead of looking at these putative foundations in a naturalistic manner, one may approach the question in a Kantian fashion: 
In order to be observed as such, these foundations must be constituted through a certain act of perception or knowledge; they cannot be independent of all frames of observation. The frame-theoretic approach allows a mode of questioning where foundations do not remain prior to the frame that allows them to be seen as foundations in the first place. Clearly, the frame of total closure itself is neither religious, nor linguistic, nor ethnic in any real sense. Reality, too, thus constituted, is not totally closed in itself. It is bounded and closed only from within the frame. This theoretical strategy implies that a national system - even in the absence of prior ethnic, religious, or linguistic unity - can constitute such unity from thin air, acting as a foundation of its own foundations. As a twist on Benedict Anderson's argument that print languages served as a medium of imagining nations, I analyze how "nation" may act as a medium of imagining a language, e.g., Hindi, now used by a large population. The sociocognitive frame behind "nation" not only selects and makes certain languages and ethnic groups more significant, turning the previously unmarked into the marked (Brekhus 1998); it also helps constitute them out of a social and cultural flux. In step with the "invention of tradition" literature (Hobsbawm and Ranger 1992), this analytical strategy helps explain how India, lacking a pre-existing common national language, was able to actively produce one, modern Hindi, from the amorphous linguistic landscape. The theoretical frame of total closure will also allow researchers of other regions, such as Serbia, Croatia, Israel or Norway, to explain the political production of language along nationalistic lines under similar pressures.

As a brief outline of the paper, I first discuss the idea of total closure in the context of nationalism, exploring how the model of nation is animated by an a priori sociocognitive frame of boundaries, ordering confused and obscure linguistic continua, religious practices, and ethnicities into definite groups, determining what could be conceived as "national." Extending the discussion of socio-mental processes of lumping supposedly homogeneous chunks of identity and splitting them off from one another as discrete entities (Zerubavel 1991), I elucidate the contours of this specific frame in all of its dimensions - social, cognitive, 
and physical, including their institutional, perceptual, and territorial effects respectively. For my analysis, I employ extensive reading of Hindi and Urdu literature as well as constructions of their respective histories, though the main focus of this article is the production of modern Hindi. To bring out the "new-ness" of Hindi, and its production as a "separate" language, I draw upon resources that provide clear evidence that linguistic closure around an imagined Hindi was pursued until late in the twentieth century. To this end, I rely on transcripts collected from the National Archives of India in New Delhi (Archives 1949), pertaining to the debates on the floor of the Constituent Assembly in 1946-49 about the status of Hindi. I also examine other relevant documents on this issue around the time of Indian independence, including newspaper and magazine articles.

\section{Institutional Effects}

There seems to be no consistency among nations in terms of what binds them together. While nationalist rhetoric tends to proclaim some essential, pre-existing real foundation, or origin -- like one culture, one ethnicity, one people -- as the constant, hidden, natural "presence" behind the nation, purporting to act as its vigorous, vital truth, different nations evoke their nation-hood on different bases. If Germany grounds its nation-hood in German ethnicity, pronouncing, for instance, in Article 11 of the German Constitution that "ethnic Germans" residing in other states are $a$ priori entitled to full German citizenship through repatriation quite in the manner of Israel's “Law of Return", France traces its national roots to an historical act of founding the republic (Best 1988). In many other instances, instead of ethnicity, race or the historical birth, it is religion that is perceived as providing the foundational content (e.g., the founding of Pakistan as a nation of Muslims).

While there is no uniformity in what nations claim to be the basis and essence of their nationhood, which lends itself to different definitions in different contexts, there is a remarkable correspondence in how these communities close off their boundaries and how they structure and 
legitimate their enclosures, including symbolic closures achieved through anthems and flags in their varying content and design (Cerulo 1995). Further, this closure may or may not be an institutionalized and statebased closure, as reflected in a cognitive orientation toward this closure in such separatist, sub-nationalist movements as Chechnya, Jaffna, Punjab, Quebec, or Sindh. The framework of institutionalized total closure and non-institutionalized total closure may help differentiate "actual" nations (i.e., nation-states) from others that may be called "possible" nations, as reflected in nationalist movements. What triggers the actualization of this possibility seems to depend on historically contingent factors. Yet, total closure is not merely institutional in character. It also informs the psychic side of the equation through a cognitive orientation that must be excited in order for it work at the level of individuals.

\section{Perceptual Effects}

One implication of collective orientation is what the Scholastics of the Middle Ages called "inexistence": a group may be intentionally oriented toward an object that does not exist or to an event that has not occurred. I will shortly describe how "Hindi" was believed to exist as a language of a vast majority of people before it actually did, an orientation that led to its actual birth as a distinct language. Such cognition can be both prospective, oriented toward a future possibility (e.g., possibility of forming a national language) and retrospective, oriented toward a past that may or may not have existed (e.g., a nation organizing a particular historical memory). Thus, we may describe the notion of collective orientation as characterized by a certain kind of directedness toward an object or event -- existent or non-existent. Suppose two groups are looking at an ambiguous drawing, such as the duck/rabbit sketch discussed in the Philosophical Investigations of Ludwig Wittgenstein (1953), and the light rays reaching their eyes from this drawing are identical. One group may perceive the image of a duck, while the other sees a rabbit, and the difference in perception is due to the viewers' structuring of what they see in the two cases, based on their 
group's orientation. "Looking at a contour map, the student sees lines on paper, the cartographer a picture of a terrain" (Kuhn 1970, p. 111). In all perception, a certain kind of cognitive structuring takes place. I extend the concept of total closure to an analysis of how nationalist collective orientation toward total closure harbors a constant possibility of conceiving and forming insular units, such as national languages and ethnic groups. The growth of Hindi and Urdu as separate national languages and Hindus and Muslims as insular communal groups may be understood as a result of such cognitive closure.

The cognitive dimension of total closure is oriented toward three interrelated features: boundedness, substantive-ness, and internal identity and external difference, the features that Richard Nisbett (2003) has associated with the Northern European tradition and style of perception. Under this perceptual regime are constructed non-continuous, discretely bounded, substantive groups as neatly divisible packages of populations, cultures, and lands, resulting in such entities as nations, races, ethnic groups, and even languages with rigid boundaries. Absolute inclusion and absolute exclusion, or what Zerubavel (1991) calls "digital thinking" is the natural idiom of total closure, and the opposition of the "self" and “other" its way of relationship. Richard Handler's (1988) argument that nationalism is an ideology concerned with boundedness, continuity, and homogeneity encompassing diversity appears to be a description not only of nationalist ideology; it might as well apply to racism as well as what Gilroy (1987) calls "ethnic absolutism." It seems to presuppose the frame of total closure that allows absolute cognitive and social boundaries to be drawn, emphasizing or de-emphasizing certain elements to produce a unity, while de-emphasizing or emphasizing others to produce a difference. In this socio-cognitive scheme, a nation is a unity of individual bodies and the world a unity of national bodies (e.g., the United Nations). The argument that the most important notion behind nation is the modern concept of the individual (Calhoun 1994; Calhoun 1993; Handler 1988) attains further clarity in view of this cognitive frame of constituting and understanding the world in terms of - to borrow from Leibniz - windowless monads. 
The logic of total closure organizes a two-fold collective orientation: first, it helps mark all the members in an enclosure as "identical," de-differentiating them in terms of their "identity." For example, all citizens of India become "Indians," assuming an essential Indian national "identity," ignoring the internal variation within the total closures thus constituted. Second, it creates a sharp, unbridgeable gulf from other groups, such as the homogenous category of Pakistanis, a process described as "lumping" and "splitting" of social flux (Zerubavel 1996). The construction of mental gaps between clusters is critical to one's ability to experience entities as closed and insular. The constitution of the bounded body is directly related to the concept of the human body as a unified entity totally separate from the world, with a complete disregard of bodily pores through which the world constantly travels, such as air inhalation and sweating, not to mention bacterial life forms that challenge and sustain the human body. In modern times, the cognitive side of total closure may be seen as a condition of the possibility of many kinds of racism--colonial racism, Nazism, colorbased racism, and what Balibar (1991) calls newly emerging forms of cultural racism in Europe targeted against alien, immigrant cultures. In terms of cognitive conditions, there seems to be little difference between race-based closure and nation-based closure; both orient themselves through the exclusivity of total closure. A discussion of the constitution of actual national boundaries further clarifies the notion of total closure.

\section{Territorial Effects}

Nations are above all characterized by absolute boundaries, by a relentless commitment to the mutual exclusivity of islands of humanity. Applying the notion of total closure to the territorial basis of nations, it is not surprising that the construction of national frontiers seems to surpass in rigidity all previous communal boundaries. Unlike the loose, fuzzy territorial limits of earlier communities, such as dynastic spaces, or empires, where borders faded indiscernibly into one another (Anderson 1991), the boundaries of nations not only rigidly demarcate one cluster of regions and populations from another; they also cut up the sky and the 
sea into exclusive national spaces. Border patrolling, border fencing, ports of entry combined with a constant vigil to guard against slightest border violations impart the national frontier an unprecedented rigidity. The importance of boundaries -- as Paasi (1996) notes in the context of Finnish-Russian border -- is not merely political; it is also social, as boundaries mold the experience of social solidarity that binds "us" in contrast to an image of difference with "them," marking not just administrative but also sociocultural transitions. Similarly, Kaiser and Nikiforova (2006), in the context of the Estonian-Russian border, have shown how borderlands are multiscaler sites where the interior and exterior of the nation and nation-ness are reconfigured. Borderlands -- as zones of contestation and spaces of becoming -- have become more, not less, important in a borderless world (Kaiser and Nikiforova 2006). The ascendency of boundaries as against the interiors of the nation is also highlighted by the decline of birth certificate and rise of passport as a form of a person's identity in recent decades (Anderson 1994).

In view of constant border disputes throughout the world, there is nothing that appears more arbitrary as a national boundary; yet, there is no other boundary system that evokes a greater awe, or arouses a stronger shock. While we may explain territoriality as the common element of the institutionalization of total closure, we must take note of its historical contingency, which allows scholars to question the framework of territorial states, especially in view of increasing political and social movements that happen outside this framework (Agnew 1994; Sassen 2006). Even within the framework of territorial states, the heavy investment of emotions and artillery into national borders seems directly proportional to the level of their arbitrariness. The line of national separation between India and Pakistan is shown differently on their respective maps, as both countries display Kashmir -- a thorny issue behind protracted post-independence hostility -- in their possession. Around the line of control, the two nations exchange gunfire on a regular basis to give an unshakable fixity to an arbitrary boundary. The greater the arbitrary-ness, the stronger the need to keep it from moving. 
The logic of total closure and associated practices not only construct categories of inclusion, such as the "citizen" or the "resident"; they also constitute at the same stroke categories of "exclusion" -- the alien, the immigrant, the refugee. Once we brush aside the "naturalness" of territorial boundaries, a clearer connection between territoriality and power relations, as pointed out by Sack (1986) and Sassen (2006), starts to emerge. The creation of "total" national enclosures produce categories of people that spill over the framework, e. g., illegal aliens or refugees, who become objects of either derision or compassion depending on the situation. Quite like the pure conceptions of the body and its dangerously anomalous categories of excreta, saliva, rheum, and genital secretions, usually despised for falling into a gray zone out of the sacred domain of the body (Douglas 1978), the conception of "nation" as a sacrosanct body gives rise to "problems" or "anomalies" to be solved by national governments that may in fact be responsible for the rise of such categories in the first place. A good example of such an anomaly is the emergence of the refugee (Malkki 1995) who is not born as an offspring of the nation; rather, the refugee flows out as its bodily discharge. In the following section, I discuss how the production of national language in India turned the existence of a variety of languages into an anomaly, a problem to be solved.

\section{Language as a Problem}

In twentieth century India, language is spoken of in terms of a crisis. It emerges as a "problem." Debates on language attain a centrality in cultural concerns, previously unseen in history. The problem status of language is reflected in the majority of books and articles written on language issues during this period in India. Our language Problem (Gandhi 1965), Problem of Hindi (Majumdar 1965), The Only Solution to India's Language Problem (John 1968), Language Problem (Bhave 1965), India's Language Crisis: A Study (Kumaramangalam 1965)--are only a few examples out of such literature in English as well as all major Indian languages. The question of language chiefly relates with three problems: first, "a" language was required to take birth in order to fulfill 
growing nationalist aspirations; second, this future language was to carry out an impossible task of binding an emerging nation together, of taming the cultural profusion of more than a hundred languages and a whole spectrum of religious practices; and third, the above tasks were to be performed without coercing the already existing linguistic subnationalisms informed in turn by the cognitive frame of total closure.

There is an easy tendency to locate the separation of Hindi and Urdu as two different languages in the division of Hindu and Muslim communalism; but in step with Gyanendra Pandey's (1990) analysis , I will discuss at length later how communalism itself was a product of a new collective orientation toward total closure. The separate histories of Hindi and Urdu ${ }^{1}$ do not stretch back, despite their claims to the contrary, to pre-British times, or pre-nationalist era. To begin with, Hindi and Urdu, even in their present forms, share common grammar at large, including common pronouns, verbs, and basic vocabulary, and speakers of both languages can follow each other; it is only their literary forms that have become mutually unintelligible because of the strong

\footnotetext{
${ }^{1}$ The literary historians of Hindi and Urdu construct and claim two very different traditions, stretching back several centuries, for their respective languages. While major historians of Hindi literature (Dwivedi 1952; Shukla 1965) construct historical links with high literary traditions of Braj and Avadhi, calling them earlier forms of Hindi despite the fact that Braj and Avadhi would not be intelligible to a Hindi speaker without a few years of training. Urdu historians, on the other hand, trace the language's roots to Dakani, and a literary tradition starting with Quli Qutub Shah (1565-1611), whose language bore a much different form than modern Urdu. Although it is a difficult task to find languages with clear boundaries and clear linear traditions, a simpler linguistic and grammatical route to history for both Hindi and Urdu would be the history of an amorphous set of dialects called Khari Boli, Hindavi, and Dehlavi, being spoken in areas around Delhi by many early writers, such as Amir Khusro (1236-1324), Abul Fazl (1551-1602), and Sheikh Bahauddin Bajan (Rai 1984; Nagendra 1995). There is in fact closer affinity in terms of intelligibility between spoken Hindi and Urdu as compared to their affinity with their professed ancestors, such as Braj, Avadhi, and Dakani. Despite widespread claims to difference in both Hindi and Urdu traditions, some writers believe that the difference is more political than cultural (King 1994; Rai 1984); yet, it is precisely the cultural difference that was being invented in the form of Monadlike parcels of language and religion. The production of Hindi and Urdu as two different languages in the nineteenth century directly correlates with the rise of a collective orientation that was creating conditions for the possibility of two future national languages out of the same linguistic raw material, and the improbability of their undivided existence.
} 
influences of Sanskrit on Hindi and of Persian and Arabic on Urdu. Both Hindi and Urdu are believed to have derived their grammar from "Khari Boli," which was widely spoken in north India with close affinities to such local variations as Dehalvi, Haryani, and Hindavi.

The processes of the Hindi-Urdu split historically began in the early nineteenth century, culminating with the India-Pakistan partition of 1947, the year of independence from the British crown. In his early linguistic work, John Gilchrist (1759 - 1841) did not treat Hindi and Urdu as two separate languages, and called them by the name Hindoostanee (or "Hindustani") reflected in the title of his work: $A$ Grammar of the Hindoostanee Language (Gilchrist 1796). It was only in 1824 that Captain Price, a successor of Gilchrist, used the two terms -"Hindee" for "Hindi" and "Hindoostanee" for "Urdu", differentiating them on the basis, not of grammar, but of vocabulary used. Price writes, "The great difference between Hindee and Hindoostanee consists in the words, those of the former being almost all Sunskrit and those the latter, for the greater part Persian Arabic..." (Vedalankara 1969, p. 51). However, this production of difference was not an unconscious development nor were the British scholars mere observers. As one of the earliest prose writers of modern Hindi, Sadal Mishra, writes in his Ramcharitra: "One day Mister Gilchrist ordered and dictated me to write spiritual Ramayana ${ }^{2}$ in a language that does not contain Persian or Arabic...Then, I started writing in Khari Boli [Hindi] and finished this book in 1862, titling it as Ramcharitra" (Mahendra 1995, p. 40)3. At the time of Indian independence in 1947, the process of the development of Persian-free Hindi as a national language and the controversies surrounding it were by no means settled.

\footnotetext{
${ }^{2}$ A story of Ram, one of the gods in Hindu theology.

${ }^{3}$ In terms of poetry, Hindi was lagging behind its counter-part Urdu, and did not produce any literature of significance until the twentieth century, reflected in the poetry of Maithili Sarana Gupta (1948) of Dwivedi school, and the more creative poetry of Nirala, Pant (1966), Varma (1951), and Prasad (1958) of the Chhayavada school in the 1930 s.
} 
To capture the collective orientation toward a national language and associated problems, there is no better site of investigation than debates on the floor of the Constituent Assembly of India regarding the status of Hindi. I closely examine all the relevant documents on this issue around the time of independence, with special reference to the transcripts of Assembly debates of 1946-49.

\section{Contested Linguistic Terrain: The Production of Modern Hindi}

Sammelana [conference] considers Hindi as the National Language. It considers Urdu as a style of Hindi, which is prevalent among the elites.

Purushottam Das Tandon in the Constituent Assembly of India, December $12,1948$.

The status of the so-called Hindustani or common language should be accepted, and it should be clear that it is only simple Urdu.

Ghazanfar Ali Khan (Patel et al. 1971, p. 70).

As stated earlier, the sociocognitive imperative to devise a national language required to fulfill, first, a functional need for a lingua franca so that different parts of the nation could talk with each other. In this task, the future national language was required to contend with English, which was promoted during the British Raj as a language of interstate administration. But English as a lingua franca still remained confined to a microscopic minority throughout the former colony. The need for a national lingua franca was expressed as follows by Ananthasayanam Ayyangar who came from a non-Hindi-speaking region and later served as the first Deputy Speaker and then Speaker of Indian Parliament:

At present, we can communicate with the foreigners due to English being the interstate language, but we remain ignorant about the cultural and literary progress in different parts of our own country. Consequently, the unification of cultural and literary progress of the country is not achieved, hindering nation's march to becoming one single whole (Varma 1997, p. 33).

A similar sentiment was expressed by another non-Hindi-speaking leader. Lakshminarayan Sahu said, "I belong to Utkal (Orissa), yet I fully agree to the adoption of Hindi as the national language." Sahu disagreed 
with his colleagues from the South who argued that Hindi should be adopted as an "official" language, the language of administration, not as a national language. T. A. Ramalingam Chettiar, in clear opposition, said, "you cannot use the word national language, because Hindi is no more national to us than English or any other language. We have got our own languages which are national languages and for which we have got the same love as the Hindi speaking people have got for their language." This line of argument gave Lakshminarayan Sahu "much pain" who argued, "When we regard India as a nation and are trying to make it one, there is no reason why we should call it official [not national] language." This brings me to the second, non-instrumental and more symbolic aspect of the sociocognitive imperative. This imagined language was to satisfy the need for national self-expression. It was to demonstrate that it could be the appropriate medium of expression of a cultural "essence," of the nation, or its national content, which was also to be selected out of a surrounding cultural profusion. The nation's ethnie was to be devised and delimited.

There is a curious fact about devising a national essence: it is not the contemporary but the most ancient that is generally found to be its most suitable expression. Sanskrit, one of the oldest languages with no "contamination" of the present, emerged as a natural choice for expressing the Indian cultural "essence." Although Sanskrit had stopped being a spoken language for about 1000 years, it was this language that was experiencing a surprising revival during the development of national consciousness, even though numerous local languages, such as Braj, Avadhi and Bengali, had replaced it, for many centuries, even as a primary medium of literary expression. It is true that regional literatures in India always showed a debt to Sanskrit with their use of Sanskrit lexicon, imagery, and myths, and a much less obvious debt to their immediate Apabhramsha past, to the dialects immediately preceding the modern Indo-European vernaculars. Yet, these regional literatures were written in regional languages. 
In the nineteenth century India, various religious reform movements, such as Brahmo Samaj in Bengal, or Arya Samaj in northern and western India, were creating a mass-based Hindu religion along the exclusive lines of Sanskrit texts, such as the Vedas and Upanishads. Arya Samaj's battle-cry "back to the Vedas" reflected this new cultural mood toward original purity. This may be called what has been termed as the "invention of tradition" where these invented traditions were oriented not only to the past but also to the future (Hobsbawm and Ranger 1992). The collective orientation of this period not only attempted to mold the present in the image of the past; it also imagined a nation-based future that did not yet exist. Absurd as it may seem, Sanskrit became one of the contenders for becoming the national language, although almost no social group in the country knew how to speak or write it fluently, and only a small minority of Brahman orthodoxy could understand it. On the floor of National Assembly, the leaders, who favored a Hindi with free borrowings from Sanskrit, opposed this idea of making Sanskrit the national language. As late as 1949, the following dialogue between national leaders shows concerns for Sanskrit in the Constituent Assembly:

Purushottam Das Tandon: I also have love for Sanskrit. I think everyone born in this nation should learn Sanskrit. It is through Sanskrit that our ancient heritage will be maintained...If it is adopted, I'll be glad, and I'll vote for it. But it seems to me that it is not a practical proposition to make Sanskrit the official language of the nation.

Pundit Lakshmi Kant Maitra: After fifteen years, it will be totally alright, though it is not so today.

Purushottam Das Tandon: I don't think that it is possible for us today to say Sanskrit should be [the national language] in place of Hindi. I think the most practical solution is that Hindi should be accepted for the purposes of administration.

If the idea of making Sanskrit the national language proved to be impractical, a Hindi that eschewed Persian and Arabic words, became the closest compromise for a nationalist orientation. For Ananthasayanam Ayyangar Hindi was the best alternative because "Hindi is closest to Sanskrit. Our most ancient culture is secure in it, and it is spoken and 
understood by the maximum number of Indians" (National Archives 1949).

However, this form of Hindi was yet not fully developed for the practical purposes of administration, despite a dense production in the first half of the twentieth century of a Hindi literature that consciously avoided commonly understood Persian and Arabic words (e.g., Chhayavada school). This literature seems to emerge as a reaction against the putative Persianization of Khari Boli at the literary hands, presumably, of the Muslim elite located mostly in Lucknow and Delhi. Yet, unlike the Persianized version, i.e., Urdu, which could boast of many non-Muslim poets, the Sanskritic version of Khari Boli appeared devoid Muslim writers during this period. But some national leaders were hopeful that eventually they would be able to develop this language, which would first act alongside English as the official language, and later replace it completely. Purushottam Das Tandon, during Constituent Assembly debates, contended, "I request that Hindi, with the assistance of Sanskrit, can solve all the difficulties of vocabulary, as has already been discussed a lot in the House. It seems to me that we will be able to perform in Hindi the work of High Court even before the end of five years." The time of five years was proposed before Hindi was to replace English as the official language of India, which was later extended many times. "Vocabulary is not a problem," he continued, some of it already exists, and after all, it is not difficult to create new words."

The argument for the construction of a Sanskritized language did not enjoy consensus in the Constituent Assembly, as brought out by the following argument between Purushottam Das Tandon and Hasrat Mohani, a prominent Urdu poet and a national leader:

Tandon: Give us enough time, and in fifteen years, it will be easier to carry out all important work, for instance the work of the federation, because by that time Hindi provinces would create an atmosphere, and would construct vocabulary that would be useful for the whole country. 
Maulana Hasrat Mohani: What do you mean by "Hindi Provinces"?

Tandon: I mean those provinces that have accepted Hindi as their official language; for instance, United province has officially adopted Hindi as its language.

Maulana Hasrat Mohani: United Province is either an Urdu province or Hindustani province. It can't be a Hindi province

Tandon: It may be your view. I do not want to engage in the debate on Hindi, Urdu, or Hindustani.

Many national leaders with a pluaralist orientation, following Gandhi, were averse to the idea of the Sanskritization of language, and to the replacement of commonly understood words, derived from Persian and Arabic, by coining Sanskrit terms for them. Some easy examples from Judicial language were words such as Qanoon meaning "law" and Vakil meaning "lawyer" that were replaced with new Sanskrit constructions, like Vidhi and Vidhivakta or Adhivakta respectively.

There were three styles being invoked in perceiving the language; Sanskritic, Persian, and common speech styles. A prominent national leader Maulana Abul Kalam Azad with his secular nationalism favored common speech, and promoted a national language that did not deliberately avoid Persian or intentionally chose Sanskrit, the two extreme ends that produced Urdu and Hindi as separate languages: "We need to produce a national language that can replace a language as broad and scholarly as English. That can be done by making its scope as wide as possible, not narrow. If you call it Urdu, it will surely not be wide. Similarly, if you call it Hindi, it again would be narrow. Only Hindustani is the word that has developed a wide understanding, and which reflects the true nature of the language." Many leaders contended that the Sanskritized Hindi that was being promoted as the national language was not even the spoken language of the majority of people, as they were made to believe:

Shankar Rao Dev: "when I go to see Rajendra Babu, and when people from Bihar come to see him, they don't speak Hindi. If I'm not wrong, Hindi is not spoken even in 
Tandonji's home. So, when you say that the majority of the country speaks Hindi, I doubt it. I can only agree that the majority of the people understands it, and even they don't understand Sanskritized Hindi, which is followed by Pundits only.

Mohandas Gandhi had long proposed "Hindustani" as the possible national language. It was an important decision for the politics of secular nationalism, which conceived a closure directed chiefly against the British, while transcending the communal closures of Hindu and Muslim nationalisms. For Gandhi, Hindustani was a practical choice, as it did represent the most commonly spoken language of north Indian urban and literate settings, and was at least widely understood in villages of the region as well. He was also aware that because of its inclusive quality, Hindustani would also stop the growing split between religious communities. In one of his speeches in 1917, he says:

It is argued that Hindi and Urdu are two different languages. It is not correct. In north India, the Hindu and Musalman speak the same language. It is the educated sections that have created the difference. It means that the educated Hindu section had made a Sanskritized Hindi, which most of the Musalman cannot understand. And Musalman brothers of Lucknow have stuffed Urdu with Persian, making it impossible for the Hindus to follow it. Both of these languages are full of punditry, without any place among the masses (Varma 1997, p. 28).

Jawaharlal Nehru, India's first Prime Minister, agreed with Gandhi's view, warning the Assembly that "we dare not live in an ivory tower of purists and precisionists...it is a dangerous thing to allow a language to become the pet child of purists and such like people because then it is cut off from the common people" (National Archives 1949). However, the purified and closed visions of language did indeed win the battle in India and Pakistan. In 1948 Ananthasayanam Ayyangar declared that the idea of Hindustani was outdated because the reason why Gandhi supported it was to promote Hindu-Muslim unity, a redundant idea after the creation of Pakistan: "Many Muslims have separated and have created their own Pakistan, declaring Urdu as its national language. In this context, there is no reason to maintain Urdu in India as well. Therefore, we should return to our real national language Hindi” (National Archives 1949). Qazi 
Syed Karimuddin resisted the idea of Sanskritized Hindi, arguing in the Constituent Assembly, "In 1947 the Indian National Congress had agreed to make Hindustani, written both in Devnagari and Urdu script as the national language of India, but today we are told that only Hindi in Devnagari script could be the national language." He contended that this change in attitude arose only in reaction to Pakistan's declaration of Urdu as its national language, and that developing a national language out of reaction was not a good idea.

The cognitive frame of communal closure eventually clinched the issue in India, and the constitution of Hindi as the official language with a heavy borrowing from Sanskrit continued at the behest of some national leaders. All Indian nationals were urged to contribute to the production of the new language. "After crowning as the National Language, it is the duty of every citizen to fill the coffer of Hindi," Ananthasayanam Ayyangar said, "the history of the kind of Hindi used in Newspapers and meetings today is not very old. It has not been long since it crystallized in its modern form through many spoken languages. In order to make new words in Hindi [for the purposes of administration], it will be natural and most appropriate to borrow from Sanskrit" (National Archives 1949).

And the Sanskritization of language was defended in the name of Sanskrit being the "natural" mother of all Indian languages, although Sanskrit, as I pointed out earlier, was a distant cousin, both temporally and grammatically, in comparison to languages of the recent past. It is also well-known that the languages of the South -- of Andhra Pradesh, Tamilnadu, Karnataka, Kerala -- belong, despite their adoption of some Sanskrit vocabulary, to a different linguistic family--Dravida, according to the linguistic system of classification. But the Hindu nationalist orientation included them as part of the same family, as expressed in the following remark by Kanhaiyalal Maniklal Munshi, Chair, National Language Council:

Modern communal institutions have spread the confusion that Hindi is being Sanskritized more than necessary. But that 
is the natural language, because its sounds, grammar, and vocabulary is borrowed from Sanskrit, which is true for the languages of Bihar, Nepal, Bengal, Assam, Odissa, Andhra, Tamilnadu, Karnataka, Kerala, Maharashtra, Gujarat, and Rajasthan.

It should be made clear that only Hindi is capable of becoming the single national language of India, because it is born out of a language that bears close similarity with Sanskrit, and it is nurtured by Sanskrit through ages, and it will have to depend on Sanskrit for further development, prosperity, and beauty. If it looks for inspiration from Sanskrit for its future power, it will easily be able to become India's national language, and the expression of its soul, the temple of beauty, a language of ancestral cultural property (Varma 1997, p. 35-37).

Munshi's assertion that the Sanskritization of Hindi will have a natural affinity with languages of non-Hindi speaking states did not stop an intense opposition to Hindi in those states, especially Tamilnadu, where anti-Hindi agitations have continued since 1938. As Hindi was scheduled to become the sole official language of India, replacing English, on January 26, 1965, the DMK, a regional political party, spearheaded a student agitation, leading, for the first time in Tamilnadu's history, to self-immolation by two DMK supporters who poured gasoline over their bodies and set themselves on fire, protesting the imposition of Hindi. In February 1965, the police opened fire in seven places, resulting in 24 deaths, and an enraged mob burnt two policemen alive in Tiruppur (Forrester 1966). This tumultuous period allowed the Tamil movement against "Hindi imperialism" to spread beyond colleges and become a sub-nationalist movement in Tamilnadu.

For the promotion of Hindi as the official language of India, the basic concern was still a clear identity separate from Urdu. The difference between Hindi and Urdu, as two national languages of India and Pakistan, needed to be exaggerated not only through the respective borrowings from Sanskrit and Persian, the putative mothers of Hindi and Urdu; there was also a need for a sharp contrast in appearance that would definitively place them as wide apart as possible. Devanagari and Persian/Arabic scripts came in handy to define what constitutes nationness in the two cases. George Grierson 1851-1941), the writer of the 
Linguistic Survey of India, did not fully grasp the pressures of total closure, as he wrote, "Among fanatics who ought to know better, but do not wish to do so, this question of characters has unfortunately become a sort of religious shibboleth...these fanatics have confused alphabet with language. They say, because a thing is written in Devanagari therefore it is Hindi, the language of Hindus, and because a thing is written in the Persian character therefore it is Urdu, the language of Musalmans" (Grierson 1967, p. xiv).

The need for separate scripts was not functional; the need was not even so much for scripts as it was for mutual separation and contrast. Hindi adopted Devanagari script of Sanskrit, which like Roman script, moves from left to right, and Urdu adopted Persian script that moves from right to left. The production of Hindi and Urdu as a contrast was mostly a conscious effort, even when the idea of India and Pakistan based on religious total closure was only a possibility. The development of institutions such as Hindi Sahitya Sammelana of Allahabad (1910) and Nagari Pracharini Sabha of Banaras (1893) for the promotion of Hindi and popularization of Devanagari on the one hand, and Anjuman-eTaraqui-e-Urdu (1903) and Urdu Defense Association of Allahabad (1898) for the promotion of Urdu, on the other, as documented by King (1994), provide ample evidence of such consciousness.

The contested terrain of language and script extended to issues of collective memory, cultural stories and historical legends. Qazi Syed Karimuddin contended, "Seth Govind Das has said that one reason for not accepting Urdu is that it contains names of Rustom and Sohrab...If we retain English [as an official language] for the next fifteen years, would it not contain stories of Lord Clive's and Warren Hasting's atrocities?" Clearly, the names of Rustom and Sohrab were invoked by Seth Govind Das to underline the cultural exclusions of the new national enclosure. The later alignment of language, religion, and nation should not come as a surprise because pressures of total closure had already structured the possible field of cultural constructions. Popular slogans 
such as "Hindi, Hindu, Hindustan" and "Urdu, Muslim, Pakistan" adequately summarize such tight cognitive closures and alignments.

\section{Hindi, Hindu, Hindustan: Urdu, Muslim, Pakistan}

The historical separation of Hindi and Urdu as two distinct languages takes place during the British rule. This is not surprising because it was during this period that the idea of nation emerged in South Asia. It was during this period that the epistemological lens of total closure became the dominant mode of social perception. Under this mode, precise packages of bounded cultural substance -- such as languages with clear boundaries, total religions, and castes, that earlier existed in the mode of relational closure -- were carved out and separated from each other. The British orientation toward classifying people as sharply closed communities and castes -- reflected in Census Report (Jones 1981; Pandey 1990; Dirks 2001) and in the language of electoral reforms -- led to a new "self-perception" among such newly constituted communities. It was during the colonial period that Muslim and Hindu identities could for the first time be constructed as closed from each other. Protonationalist aspirations necessitated a cognitive split for the production of a new future, new people, and a new history -- a new imagination and a new memory.

It is commonly argued that the formation of India and Pakistan as separate nations was a result of a pre-existing religious divide. In accordance with my earlier explication of collective orientation, where a group may be intentionally oriented toward an object that does not exist or to an event that has yet not occurred, I contend that India and Pakistan were not a result of a pre-existing absolute divide between Hinduism and Islam; rather, a major communal divide between Hindus and Muslims occurred due mainly to a new orientation toward communal closures, which at the time did not fully exist. I do not wish to imply that Hindu and Muslim communities, prior to this divide, lived in a state of Arcadian harmony; yet, the variation especially in Hindu religious practices was too large and the collective orientation too diffused and relational to 
permit the extensive, unprecedented Hindu-Muslim confrontation, including frequent communal riots and wide-spread bloodshed, that took place in the twentieth century South Asia. Thus, it was during the colonial period that Hinduism became "a" religion. Earlier, it was a spectrum of religious practices without a single prophet or a single sacred book or a single God at its center, ranging from a belief in Saguna God with human attributes (i.e., idol worship) and a more philosophical belief in Nirguna God, who is without attributes and therefore indescribable, to a religious silence about God. As Paul Brass (1974) has argued what we generally consider as "givens" or objective characteristics of a society, such as language or religion, are neither "givens" nor "objective," and both can be altered by political struggles for one symbol to be primary, and efforts to make other symbols conform.

The new social lens of total closure had effects of liberation as well. It generated proto-nationalisms not only of Hindu and Muslim types; it also gave rise to caste-based nationalisms, reflected in the Dalit movement initiated by Dr. Bhimrao Ambedkar, who demanded a separate electorate in the 1930s for the traditionally oppressed castes, as well as language-based nationalisms in various provinces. However, internal caste divisions were often overlooked in the larger program of Hindu nationalism, which was constituted mostly in opposition to a supposed Muslim enclosure. As an example of this orientation toward total closure, I cite--not any rabid communal leader--but a leader of Hindi Sahitya Sammelana (Hindi Literary Academy)--who understands Hindu and Muslim cultures as not only "different" but also "oppositional," despite the fact that people of both Hindu and Muslim faith in South Asia can be said to share various forms of culture -- music, languages, and modes of interaction -- in all their regional variations:

It is necessary to understand the nature and psychology of the Musalman and Islam, because this opposition [between Hinduism and Islam] occurs not only at the level of language [e.g., Hindi and Urdu], but also in the realms of culture and faith. Whatever historicity Islam has gained during the medieval times is not due to its greatness of thought or 
civilization, but only to its bellicosity. The whole medieval history of Europe, Asia, and Africa is a result of this Islamic tendency, due to which many civilizations were cut off from their ancient history. Rare libraries of knowledge and thought were destroyed. What remained was an empire of terror and a milieu of imposed monotheism. Whenever they [Muslims] came in contact with greater societies, civilizations, and cultures, they tried to totally destroy them. India, too, was a victim of this bellicosity... ${ }^{4}$ (Mehata 1996, p. 5)

The nationalist construction of history in terms of "invading" Muslim and "invaded" Hindu groups was not about history; it was a present need under the new collective orientation.

Hindu nationalist orientation began in the form of the Swadeshi movement, which explicitly opposed British rule and implicitly battled against past Muslim rule in a newly constituted historical memory that identified the Muslims of India, many of whom were poor and converted lower caste Hindus, with the Muslim kings of the past. The Swadeshi movement of 1905 in Bengal began with a protest against the partition of Bengal by the British that severed its Muslim-dominated part and joined it with Assam (Pandey 1979). Curiously, the anti-partition movement also gave rise to a disguised Hindu nationalism led by B.G. Tilak who initiated Ganapati ${ }^{5}$ and Shivaji ${ }^{6}$ festivals that supposedly sought to arouse Hindu vitality out of its national slumber. The nationalist struggle of the Tilak variety was simultaneously opposed to the British and Muslims by carefully choosing Hindu symbols, gods and icons (e.g., Ganapati and Shivaji) for a nationalist struggle and avoiding symbols that may have Islamic reference. What is usually termed as Hindu revivalism was bringing into existence a new Hindu identity (Chatterjee 1986) under a new collective orientation of total closure. As Kenneth Jones (1976) has demonstrated, Arya Samaj, a north Indian religious reform movement started by Dayananda Saraswati, was not merely in

\footnotetext{
${ }^{4}$ This as well as all other translations from non-English texts are my own, unless otherwise indicated.

${ }^{5}$ One of the Hindu gods.

${ }^{6}$ Shivaji Bhosle 1627-1680) is historical figure usually portrayed as a Hindu challenger to the Mughal emperor Aurangzeb.
} 
conflict with the previous Hindu orthodoxy; one of its factions -- namely, Gurukul -- articulated a new militant Hindu consciousness with blatant anti-Islamic postures. Quite like organizations mentioned earlier for the promotion of Hindi, numerous organizations such as Anushilan Samiti (1901), Rashtriya Swayam Sewak Sangh (1925), and Hindu Sabha (1910) emerged to constitute a "masculinist," militant Hinduism (Wakanker 1995). These Hindu organizations were creating a Hindu community that did not exist earlier, at least, in the same form. The movements for Sangathan and Shuddhi, literally meaning "unification" and "purity" were geared toward converting ambiguous categories of people into pure Hindus. For instance, great efforts for the conversion of the Muslims back to Hinduism were made in the United Provinces, Punjab, and Rajputana. A Muslim historian Qureshi (1985) has chronicled that there was a community of Muslim Rajputs, called Malkanas, who still retained many Hindu customs. They seemed to be an easy target, because they were proud of their Rajput blood and had not been fully assimilated into the Muslim community. The full vigor of the Shuddhi movement was turned upon them and the efforts of the Hindu workers began to bear some fruit. Qureshi (1985) not only points out that the Muslims did lose a fair number of the Malkanas; he also admires that the remaining Malkanas were not only loyal, but became better adherents of Islam, having given up their "un-Islamic" customs and ideas. A communal orientation toward total closure seemed to be ordering Hindus as well as Muslims into two neat windowless unities.

Muslim nationalist orientation, on the other hand, sought to develop a new Muslim consciousness for a new identity and selfawareness. Any prior consciousness among Muslims to see themselves as a totally separate community either did not exist, or was secondary to other concerns. Sayyid Ahmad Khan was one of the first to stress the need to make the Muslims of the Indian sub-continent aware of their "identity." In 1888, he was also one of the first to refute the idea of one nation, pointing out the possibility of other parcels of peoples and cultures, that is, other possible nations within India. He wrote to another national leader Badruddin Tyabji: "I do not understand what the words 
"National Congress" mean. Is it supposed that the different castes and creeds living in India belong to one nation, or can become one nation, and their aims and aspirations be one and the same?" (Pandey 1979, p. 15). Sayyid Ahmad Khan's ideas eventually led to the formation of AllIndia Muslim League in 1906 that played a major role in the constitution and consolidation of Muslims as a community in India, promoting among them a corporate unity.

During the struggle for independence from Britain in India, one witnesses a simultaneous struggle for the formation of Hindu and Muslims as separate communities by exaggerating the distance between them, and reducing the distance within the communities thus constructed, such as among various castes and sects in the newly conceived Hindu community. Surprising as it may seem, the exaggerated purity of Hindu and Muslim cultures was not old or archaic, but remarkably new, instigated through a well-known "divide and rule" British policy after the revolt of 1857 . Both groups endeavored to purge their cognitively closed cultures of common folk symbols and elements. Rafiuddin Ahmed (1981) has demonstrated how ulema -- Muslim religious leaders -launched a major offensive in late nineteenth century Bengal villages against folk religious practices like pirs, milad, urs, and the wearing of tabiz, labeling such practices as un-Islamic borrowings from Hindu customs. Middle class muslims in Bengal began re-inventing themselves as "foreign-born" ashrafs, resulting in the sharp increase in the 1901 census in the number of Shaikhs, Syeds, Mughals and Pathans, respectable groups devoid of Hindu caste associations (Ahmed 1981; Sarkar 2006). Thus, a new orientation triggered a split along HinduMuslim lines in a Bengali-speaking community. The production of Hindi and Urdu as national languages of the then possible nations -- India and Pakistan -- directly corresponds with this struggle for communal total closure. Under the pressure of two potential nations, a common daily language of north India was stretched and split into two. The linguistic foundations for the two nations were therefore provided by the same a priori sociocognitive frame that informed the notion of two completely separate communities. 


\section{Limits of Total Closure}

There are two different dimensions along which the frame of total closure confronts its actual and possible limits. First, there is a large arena of social practice that simply disregards the boundaries of such a frame. The historical purification of language, Alok Rai (2001) contends, has been a "narrative of the violence that has been done to the people's vernacular Hindi by and in the name of 'Hindi,' the Sanskritic usurper," but this violence has not been successful, he argues, "you cannot actually stamp out the grass. It persists in hidden corners, it springs back to life." For instance, a majority of films produced by one of the biggest film industries in the world, now popularly labeled as Bollywood, has never followed the tight closures of Hindi-Hindu-Hindustan, thus, loosening the hold of linguistic nationalism on popular consciousness. Its language has remained what purists on either side may perceive as a medley but a medley which does not follow any previously pure forms; rather, a medley that precedes purifications.

The second dimension pertains to a historical shift: globalization. Just as modern industrial societies with mechanisms of print, literacy, census, and other classification systems (Anderson 1991; Gellner 1983) enabled the frame of total closure to attain centrality in social organization, certain transformations of late modernity enable spaces where the frame starts fraying at the edges. With digital formations of the last few decades, national enclosures have been slowly pried open to an instantaneous traffic in cultural symbols through communication technologies, untying the assumed bond between culture and territory. The notion of closed territorial states, a geographical assumption of the international relations theory, has been called into question (Agnew 1994). With the increased integration of the world economy and the emergence of political movements outside the framework of territorial states, Agnew (1994) suggests to move away from the notion of states as fixed units of sovereign space with the domestic/foreign polarity. Globalization is also shifting the citizen's exclusive relationship to the state (Sassen 2006), especially with an enormous rise in dual citizenships 
offered by states in recent years, creating a situation in which different groups have different bundles of citizenship rights; e.g., India has recently enacted a program of the Overseas Citizenship of India (OCI) that offers economic but not political rights. Finally, globalization has meant the increased migration of workers and professionals whose allegiances defy the easy logic of nationalism or patriotism, marking a possible shift away from the cognitive frame of total closure. The question of nationalism becomes less urgent to a portion of this transnational population that may consist of undocumented Mexican workers in the United States whose children are documented citizens, producing a situation where adults and children have different nationalities within the same family; or Indian professionals who in their complex transnational orientation display a continuous nostalgia for the "other" nation; that is, they miss India while in the United States and long for American life when they go back to India (Aneesh 2004).

\section{Conclusion}

There is a common tendency to find some underlying cultural uniformities to explain divisions of nationalism. Thus, one may be tempted to emphasize the separation between Hinduism and Islam as the primary cause for the formation of India and Pakistan as two nations. Divisions of religion, language, and scripts, acting as what Anthony Smith (1987) calls ethnie, are considered significant factors behind the rise of two nations (King 1994). I have explored how the reality of "nation," instead of being founded upon a primordial "ethnie," is dependent on the frame of total closure, which helps organize, articulate, and construct a particular set of ethnie. Instead of focusing on substantive issues of language or religion that presumably shape nations, I have attempted to analyze how nations, languages, religions are boundary constructs informed by a collective orientation toward total closure. Patterns of linguistic, religious, or ethnic struggles vary widely from region to region; what remains constant is the ideal of clean, absolute boundaries. The frame of total closure acts as a condition of possibility for clearly defined languages, such as Hindi or Urdu, or 
tightly closed communities, such as Hindus and Muslims, or nations such as India and Pakistan. In order to formalize what nationalism imagines to be a national language, it needs to arrest its movement, fragment it, redistribute it in a new table of national "essences."

This study concludes that what is more significant is not if the nation is a modern phenomenon, whether or not it is a myth or reality; rather, the most significant aspect of the nation is the generation of reality through a particular socio-cognitive frame. Nationalist struggles need not only be directed against a colonial power; they also inform other struggles, movements, and orderings of culture even within nations, as described in the bloody opposition to Hindi in Tamilnadu. In the case of the Indian sub-continent, this cognitive frame not only gave rise to the Indian nation during its struggle against the British; it also aroused numerous efforts at local closures of languages, religions, and ethnicities against each other. The colonial propensity for the neat classification of populations, religions, and languages itself embodied cognitive structures of total closure. While one can easily link modern nations to prior ethnic streams of symbols, myths, and cultural artifacts, these prior forms are recognized as clear unities through a specific a priori cognitive frame that acquires an institutional basis in modern times.

In this article, I hope to have shown the cognitively ordered surfaces and boundaries with which a nation tames the internal incongruities of actual and possible languages; how a national space gets created upon which it is possible to encompass and inscribe people, languages, and religious practices. In this analysis, the nation emerges as a method of "holding together" informed by an a priori cognitive frame that helps organize the blurry landscape of linguistic, ethnic, and religious flows. It provides a way to define groupings and splittings, acting as a system of perception by which resemblances and differences can be shown and boundaries can be drawn; it renders precise the cognitive threshold above which there is difference and below which there is similarity. National order shows the hidden scheme that determines the way social life confronts itself. It also acts as a code on 
the basis of which languages, religious practices and beliefs are criticized and rendered valid or invalid. The carving of religions out of religious practices, languages out of linguistic continua, and ethnic islands out of patterns of social interaction are all examples of the cognitive scheme of total closure. Yet, these closures in practice are far from "total," engendering conflicts among, and the suppression of, various modes and ways of life that resist totalization.

Regardless of internal differences that irremediably plague all nations, the idea of the nation looks forward to a bounded, substantive unity with an essence. The creation of Hindu and Urdu was a result of such orientation toward finding the "essences" of two communities constituted afresh in nineteenth century South Asia. When India and Pakistan were actualized as nations in 1947 through the institutionalized means of territorial distribution, the idea of bounded and substantive unity also needed to be enforced. The communities, now intensely conscious of their Hindu and Muslim-ness, moved to their new nations, resulting in unprecedented mass migration and exchange of populations across the newly constituted borders. The large-scale move consumed roughly one million lives, turning Hindu and Muslim identities into what Appadurai (2006) has called "predatory identities." Hindus living in what was then declared Pakistan needed to move back to India, and selfconscious Muslims living in India slowly traveled toward Pakistan. Families moved from their places of birth so that they could join what was now supposed to be their "natural" nation. 


\section{References}

Agnew, J. 1994. The territorial trap: the geographical assumptions of international relations theory. Review of International Political Economy: 53-80.

Ahmed, Rafiuddin. 1981. The Bengal Muslims, 1871-1906: a quest for identity. Delhi ; New York: Oxford University Press.

Albrow, Martin. 1997. The global age: state and society beyond modernity. Stanford, CA: Stanford University Press.

Anderson, Benedict. 1991. Imagined communities: reflections on the origin and spread of nationalism. New York: Verso. 1994. Exodus. Critical Inquiry 20: 2 (Winter): 314-327.

Aneesh, A. 2004. "Between Fantasy and Despair: The Transnational Condition and High-Tech Immigration," In Donna Gabaccia and Colin Wayne Leach (ed), Immigrant Life In the US: pp. 51-64. New York: Routledge.

Aneesh, A. 2001. "Nation-ist Frame and National Identities: Producing National Languages for India and Pakistan," American Sociological Association. Anaheim, CA.

Appadurai, Arjun. 2006. Fear of small numbers : an essay on the geography of anger. Durham: Duke University Press.

Archives. 1949. Transcripts of the Constituent Assembly of India. New Delhi: National Archives.

Balibar, Etienne. 1991. "Is there a neo-racism?" In Etienne Balibar and Immanuel Wallerstein (eds), Race, Nation, Class: Ambiguous Identities. New York: Verso.

Best, G. 1988. "The Permanent Revolution: The French Revolution and Its Legacy." Chicago: The University of Chicago Press.

Bhave, Vinoba. 1965. Language Problem. Varanasi: Sarva Seva Sangh.

Brass, Paul R. 1974. Language, religion and politics in North India. London: Cambridge University Press.

Brubaker, R, M Loveman, and P Stamatov. 2004. Ethnicity as cognition. Theory and Society 33: 1: 31-64.

Brubaker, WR. 2001. Cognitive perspectives. Ethnicities 1: 1: 15.

Calhoun, Craig. 1993. Nationalism and Ethnicity. Annual Review of Sociology 19: 211-239.

Calhoun, Craig J. 1994. Nationalism and the public sphere. Toronto: Robert F. Harney Professorship and Program in Ethnic Immigration and Pluralism Studies University of Toronto.

Cerulo, Karen A. 1995. Identity designs: the sights and sounds of a nation. New Brunswick, N.J.: Rutgers University Press.

Chandra, Bipan. 1988. "India's struggle for independence, 1857-1947." Delhi: Penguin Books.

Chatterjee, Partha. 1986. Nationalist thought and the colonial world: a derivative discourse? London, U.K.: Zed Books for the United Nations University.

Das, Veena. 1990. Mirrors of violence: communities, riots and survivors in South Asia. Delhi ; New York: Oxford University Press.

DiMaggio, Paul. 1997. Culture and Cognition. Annual Review of Sociology 23: 263-287.

Dirks, Nicholas B. 2001. Castes of mind: colonialism and the making of modern India. Princeton, N.J.: Princeton University Press.

Douglas, Mary. 1978. Purity and danger: an analysis of concepts of pollution and taboo. London: Routledge and K. Paul. 
Dwivedi, Hazariprasad. 1952. Hindi sahitya ka adikala. Patana: BiharaRashtrabhasha-Parishad.

Fishman, Joshua. 1968. "Social theory and ethnography: neglected perspectives on language and ethnicity in Easter Europe," In P.F. Sugar (ed), Ethnic diversity and conflict in Eastern Europe. Santa Barbara: ABC-Clio.

Forrester, DB. 1966. The Madras anti-Hindi agitation, 1965: Political protest and its effects on language policy in India. Pacific Affairs 39: 1/2: 19-36.

Gandhi, Mohandas Karamchand. 1965. Our language problem. Bombay: Bharatiya Vidya Bhavan.

Geertz, Clifford. 1963. "The integrative revolution," In Clifford Geertz (ed), Old societies and new states. Harmondsworth: Penguin.

Gellner, Ernest. 1983. Nations and nationalism. Oxford, England: Blackwell.

Gilchrist, John Borthwick. 1796. A grammar of the Hindoostanee language; or, Part third of volume first, of a system of Hindoostanee philology. Calcutta,.

Gilroy, Paul. 1987. "There ain't no black in the Union Jack": the cultural politics of race and nation. London: Hutchinson.

Goffman, Erving. 1974. Frame Analysis: An Essay on the Organization of Experience. Cambridge, Mass.: Harvard University Press.

Grierson, George Abraham. 1967. Linguistic survey of India. Vol. IX, Part 1, pp. xiv, 49. Delhi,: Motilal Banarsidass.

Gupta, Maithili Sarana. 1948. Jayadratha-vadha, khanda kavya. Jhamsi: Sahitya-Sadana.

Handler, Richard. 1988. Nationalism and the politics of culture in Quebec. Madison, Wis.: University of Wisconsin Press.

Hobsbawm, E. J. 1992. Nations and nationalism since 1780: programme, myth, reality. Cambridge England ; New York: Cambridge University Press.

Hobsbawm, Eric, and Terence Ranger. 1992. The Invention of tradition. Cambridge England ; New York, NY, USA: Cambridge University Press.

Hutchinson, John. 2000. Ethnicity and modern nations. Ethnic and Racial Studies 23: 4: 651-669.

John, K. K. 1968. The only solution to India's language problem. Ann Arbor: University of Michigan Press.

Jones, Kenneth W. 1976. Arya dharm : Hindu consciousness in 19th-century Punjab. Berkeley: University of California Press.

_. 1981. "Religious identity and the Indian census," In N. Gerald Barrier (ed), The census in British India: New Perspectives. Delhi: Manohar.

Kaiser, Robert, and Elena Nikiforova. 2006. Borderland spaces of identification and dis/location: Multiscaler narratives and enactments of Seto identity and place in the Estonian-Russian borderlands. Ethnic and Racial Studies 29: 5: 928-958.

King, Christopher Rolland. 1994. One language, two scripts: the Hindi movement in the nineteenth century North India. Bombay: Oxford University Press.

Kuhn, Thomas S. 1970. The structure of scientific revolutions. Chicago: University of Chicago Press.

Kumaramangalam, S. Mohan. 1965. India's language crisis: a study. Madras: New Century Book House.

Luhmann, Niklas. 1984. Social systems. Stanford, Calif.: Stanford University Press.

Mahendra. 1995. "Bhashatantra: Nagar ki Boli," In Nagendra (ed), Hindi bhasha aura sahitya ke vikasa me Dilli ka yogadana: p. 353. Nai Dilli: Hindi Buka Sentara.

Majumdar, Asoke Kumar. 1965. India's Language Crisis: a study. Bombay: Bharatiya Vidya Bhavan. 
Malkki, Liisa H. 1995. Purity and exile: violence, memory, and national cosmology among Hutu refugees in Tanzania. Chicago: University of Chicago Press.

Nagendra. 1995. "Hindi bhasha aura sahitya ke vikasa me Dilli ka yogadana," p. 353. Nai Dilli: Hindi Buka Sentara.

Nisbett, Richard E. 2003. The geography of thought: how Asians and Westerners think differently-- and why. New York: Free Press.

Paasi, Anssi. 1996. Territories, boundaries, and consciousness: the changing geographies of the Finnish-Russian border. Chichester, England; New York: J. Wiley \& Sons.

Pandey, B.N. 1979. "The Indian Nationalist Movement, 1885-1947: select documents." New York: St. Martin's Press.

Pandey, Gyanendra. 1990. The construction of communalism in colonial north India. Delhi ; New York: Oxford University Press.

Pant, Sumitra Nandan. 1966. Chidambara. Delhi,: Rajakamala Prakasana.

Patel, Vallabhbhai Jhaverbhai, Durga Das, and Shankar Prasada. 1971. Sardar Patel's correspondence, 1945-50. Ahmedabad,: Navajivan Pub. House.

Prasad, Jai Shankar. 1958. Kamayani. Ilahabada: Bharati Bhandara.

Qureshi, Ishtiaq Husain. 1985. The Muslim community of the Indo-Pakistan subcontinent, 610-1947 : a brief historical analysis. Delhi: Renaissance Pub. House.

Rai, Alok. 2001. Hindi nationalism. Hyderabad, A.P.: Orient Longman.

Rai, Amrit. 1984. A house divided : the origin and development of Hindi Hindavi. Delhi ; New York: Oxford University Press.

Sack, RD. 1986. Human territoriality: its theory and history: Cambridge University Press.

Sarkar, Mahua. 2006. Difference in memory. Comparative studies in society and history 48: 01: 139-168.

Sassen, Saskia. 2006. Territory, authority, rights: from medieval to global assemblages. Princeton, N.J.: Princeton University Press.

Shils, Edward. 1957. Primordial, personal, sacred and civil ties. British Journal of Sociology 7: 113-145.

Shukla, Ram Chandra. 1965. Hindi sahitya ka itihasa. Kashi: Nagari pracarini Sabha.

Smith, Anthony D. 1987. The ethnic origins of nations. Oxford, UK New York, NY, USA: B. Blackwell.

Vail, Leroy. 1989. The Creation of tribalism in Southern Africa. Berkeley: University of California Press.

Varma, Maha Devi. 1951. Niraja. Prayaga: Indiyana Press.

Varma, Vimlesh Kanti. 1997. "Hindi: rashtrabhasha se rajabhasha tak (1947 se 1950 tak ke dastavez)." New Delhi: Prakashan Vibhag.

Vedalankara, Sarada Devi. 1969. The development of Hindi prose literature in the early nineteenth century, 1800-1856 A.D. Allahabad: Lokbharti Publications.

Wakanker, Milind. 1995. Body, Crowd, Identity: Genealogy of a Hindu Nationalist Ascetics. Social Text 14: 4 (Winter): 45-65.

Wittgenstein, Ludwig. 1953. Philosophical investigations. New York: Macmillan.

Zerubavel, Eviatar. 1991. The fine line: making distinctions in everyday life. Chicago: University of Chicago Press. 1996. Lumping and Splitting: Notes on Social Classification. Sociological Forum 11: 3: 421-433.

. 1997. Social mindscapes: an invitation to cognitive sociology. Cambridge, Mass.: Harvard University Press. 